\title{
A "PERSONALIDADE VIGOROSAMENTE FORMADA", EM GRAMSCI, E OBSTÁCULOS NO ÂMBITO DO ENSINO MÉDIO
}

\author{
E. G. OLIVEIRA
}

Instituto Federal de Educação, Ciência e Tecnologia do Ceará elenilce@ifce.edu.br

Artigo submetido em agosto/2016 e aceito em agosto/2016

DOI: $10.15628 /$ holos.2016.4996

\section{RESUMO}

Esta abordagem destaca, em Gramsci, a categoria "personalidade vigorosamente formada" no epicentro de suas preocupações com a Educação e evidencia a difícil de contribuir para uma personalidade assim constituída, na Educação do Brasil, onde prevalece a vertente educacional de base conservadora e individualista.

PALAVRAS-CHAVE: Ensino Médio, Educação, Gramsci

\section{THE "PERSONALITY STRONGLY FORMED" IN GRAMSCI AND OBSTACLES IN SECONDARY EDUCATION SCOPE}

\section{ABSTRACT}

This approach highlights, in Gramsci, the "vigorously formed personality" category as education related concerns and evidences the hard task of forming and ensuring a High School capable of contributing to a set personality, in Brazil's education, dominated by a conservative and individualist base.

KEYWORDS: High School, Education, Gramsci 


\section{INTRODUÇÃO}

O homem deve ser concebido como um bloco histórico de elementos subjetivos e individuais e de elementos de massa e objetivos ou materiais, com os quais o indivíduo está em relação ativa. Transformar o mundo exterior, as relações gerais, significa fortalecer a si mesmo, desenvolver a si mesmo. É uma ilusão e um erro supor que o "melhoramento" ético seja puramente individual: a síntese dos elementos constitutivos da individualidade é "individual", mas ela não se realiza e desenvolve sem uma atividade para fora, transformadora das relações externas, desde aquelas com a natureza e com os outros homens em vários níveis, nos diversos círculos em que se vive, até a relação máxima, que abarca o gênero humano. Por isso, é possível dizer que o homem é essencialmente "político", já que a atividade para transformar e dirigir conscientemente outros homens realiza a sua "humanidade", a sua "natureza humana". (GRAMSCI, 2006a, p. 406-407).

Nos últimos três anos, o medo, a angústia e a incerteza retornaram ao cotidiano dos brasileiros. Nas ruas desfilam as bandeiras de cetim, os cartazes em letras cintilantes, as panelas em aço inox, as buzinas dos carros; nos prédios, as luzes em pisca-pisca acendem e apagam freneticamente, improvisando uma música inaudível. Em outros tempos, nas manifestações de ruas - planejadas e executadas por frações da classe trabalhadora - arrastavam-se poucos carros cuja lataria era coberta quase integralmente com cartazes colados pela multidão que os seguia a pé, em meio a muito suor e confrontos com a polícia. Misturavam-se os sons dos gritos de dor decorrentes do uso de cassetetes empunhados pelos agentes repressores do aparelho de Estado - com as palavras de ordem ensaiadas pelos portadores da luta por trabalho, terra, moradia, educação e saúde. Dessa maneira, evidenciam-se mudanças nos sujeitos e no conteúdo da mensagem das ruas. Hoje são provenientes de frações da classe trabalhadora, que alcançou, de um lado, a elevação da escolaridade e, de outro, o aumento do poder aquisitivo para o consumo de bens e serviços. Suas palavras de ordem, afixadas em cartazes e faixas, centram-se na redução da carga tributária, na prisão de corruptos e na expulsão (!!!) das ideias de Karl Marx, Antonio Gramsci e Paulo Freire.

Nessa nova modalidade de manifestações, chamou-me a atenção a ojeriza a Gramsci e Paulo Freire. Por certo, esses dois ativistas político-pedagógicos contribuíram para a compreensão dos nexos entre Educação e Sociedade, visando à edificação de outras relações sociais, onde prevaleçam o senso de coletividade, dignidade e humanidade. Não seria esse, ao final de contas, um projeto de interesse geral? Certamente, sim. Particularmente, o conteúdo das mensagens dos cartazes acerca de Gramsci e Paulo Freire em manifestações ocorridas no período junho de 2013 a julho de 2014 levou-me a um estado de choque, preenchido com interrogações e silêncio.

Ora, é sabido o quanto os escritos de Gramsci - introduzidos no Brasil por Paolo Nosella, Marco Aurélio Nogueira, Leandro Konder, Carlos Nelson Coutinho e Edmundo Dias, entre outros permearam a produção científica brasileira, por meio de teses e dissertações. Nos últimos catorze anos, conforme banco de dados da CAPES, as categorias gramscianas norteiam 139 teses e dissertações, defendidas em 147 universidades brasileiras. Dessas, a Universidade Federal do Ceará ocupa a posição de liderança, com 12 defesas; a Universidade Federal Fluminense, 11; a Universidade Estadual do Rio de Janeiro, 11; a Universidade Estadual de Campinas, 8; a 
Universidade de São Paulo, 8; e assim por diante (CAPES, 2015). Nesse mesmo período, o banco de dados do Instituto Brasileiro de Informação, Ciência e Tecnologia registra 428 referências a Gramsci em quaisquer partes das teses e dissertações, destacando-se a Universidade de Campinas, 49; a Universidade Federal de Santa Catarina, 33; a Universidade de São Paulo, 33; a Universidade Estadual do Rio de Janeiro, 26; a Universidade de Brasília, 25e Universidade Federal do Ceará, 23 (IBICT, 2015).

De fato, os escritos de Gramsci constituem embasamentos relevantes na produção científica brasileira e também nas reflexões em outros espaços educativos, sobretudo nos círculos influenciados pelo propósito da edificação de uma sociedade mais humana e igualitária na qual os interesses individuais não se sobreponham aos proveitos gerais.

Considerando que as categorias gramscianas contribuem para a compreensão da realidade, cabe ressaltar o fato de que este ensaio tem suporte nas contribuições gramscianas, sobretudo os seus cadernos e cartas do cárcere. Nele ressalto a noção da personalidade vigorosamente formada (em seu senso de coletividade) como o centro do processo educativo, em Gramsci. Ao mesmo tempo, destaco alguns elementos que se revestem em obstáculos para instituí-la e constituí-la, sobretudo no Ensino Médio brasileiro.

Preliminarmente, chamo a atenção para duas observações: 1) o tratamento da noção de personalidade em Gramsci não se reduz à dimensão psicologizante; 2) a categoria personalidade vigorosamente formada passou ao largo dos estudos acadêmicos, haja vista que, nas últimas décadas, se concentrou, de um lado, na defesa do Ensino Médio; e, de outro, no ensino Médio Integrado à Educação Profissional, sem, contudo, denotar novos elementos categoriais, visando a contribuir para a melhoria e transformar a Educação brasileira. Deriva daí a elaboração deste ensaio.

\section{A EDUCAÇÃO EM GRAMSCI}

Destaco, inicialmente, a Carta 323, de 10 de agosto de 1932, destinada à sua mulher, Giulia. Nela, Gramsci tece argumentos acerca da propensão profissional de seus filhos: Delio, oito anos de idade, e Giuliano, seis anos, relembrando à esposa acerca da inclinação profissional de Delio para a Engenharia, e logo substituída por Literatura e Poesia. Em relação a tal estado de coisas, Gramsci é conclusivo:

$\mathrm{Na}$ verdade, devo dizer, que não acredito nestas inclinações genéricas tão precoces (...). Acredito que, em cada um deles [os filhos, Delio e Giuliano] coexistam todas as tendências, tal como em todas as crianças, tanto para a prática quanto para a teoria ou a fantasia, e que, de fato, seria correto guiá-los neste sentido, para um ajuste harmonioso de todas as faculdades intelectuais e práticas, que podem se especializar em tempo apropriado, com base numa personalidade vigorosamente formada em sentido total e integral (GRAMSCl, 2005b, p.224-225). (Grifos).

Nesse conhecido trecho, Gramsci destaca três categorias basilares: em primeiro lugar, a noção de homem como ser integral, em que coexistem pensamento e ação, intelecto e práticas; depois diz respeito ao tempo apropriado para as especialidades (curso técnico ou superior ou ainda 
o exercício imediato de profissão); e, por fim, acentua a "personalidade vigorosamente formada" como o alicerce ou a base comum sobre a qual se ajustam as capacidades do intelecto e das práticas.

Se a "personalidade vigorosamente formada" constitui a base da Educação do homem entendido como ser integral - cabe esclarecer, de um lado, o fato de que sua noção de homem não se restringe à pessoa e, por isso, não é exclusivamente psicológica; de outra parte, não se reduz às relações sociais, pois o homem é também o conjunto das condições de sua vida. E não basta haver condições objetivas de existência, pois é preciso conhecê-las e delas querer usufruir (e isto se aplica também às possibilidades). O homem, no entanto, também é vontade concreta, ou seja, aplica o seu querer em meios concretos capazes de realizar sua vontade. Ao explicitar sua noção de homem, Gramsci, em seu caderno 10, v.1, descreve a maneira pela qual a personalidade se forma: 1) dando uma direção determinada e concreta ("racional") ao próprio impulso vital ou vontade; 2) identificando os meios que tornam esta vontade concreta e indeterminada e não arbitrária; 3) contribuindo para modificar o conjunto das condições concretas que realizam esta vontade, na medida das próprias forças de maneira mais frutífera. (GRAMSCl, 2006a, p. 406).

Nesse sentido, a "personalidade vigorosamente formada" requer, em conformidade a Gramsci, em sua Carta 323, uma educação capaz de reunir em um só homem (Grifos) as seguintes características:

[...] o engenheiro americano, o filósofo alemão, o político francês, recriando, por assim dizer, o homem italiano do Renascimento, o tipo moderno de Leonardo da Vinci transformado em homem-massa ou homem coletivo, ainda que mantendo sua personalidade e originalidade individual. Uma coisa à toa, como você pode ver. [...]. (GRAMSCl, 2005b, p.225).

O relevante nesse exemplo fornecido por Gramsci é a conjugação ou interação do homem coletivo com o âmbito individual. Não se reporta, contudo, ao prolongamento do tempo escolar, mas se refere aos esforços para a conjugação de características que visam ao equilíbrio das funções intelectuais e práticas, pensamento e ação. Nesse processo, não se destrói a personalidade individual, uma vez que os traços do passado se mantêm no presente.

A noção de "personalidade vigorosamente formada" em sentido total e integral também é uma personalidade coletiva resultante dos enfrentamentos consigo e com os outros, além de tentativas de conformações à vida social. A esse respeito, cabe consultar o registro da Carta no 285, dirigida a Tânia, sua cunhada, em 15 de fevereiro de 1932:

Todo mundo elabora e desenvolve, a cada dia, a própria personalidade e o próprio caráter, luta com instintos, impulsos, tendências negativas e anti-sociais, e se adapta a um nível de vida coletiva cada vez mais alto. Nisso não há nada excepcional, individualmente trágico. Todo mundo aprende com seus próximos e afins, cede e avança, perde e ganha, esquece e acumula noções, traços e hábitos. Giula escreveu que, hoje, não mais se defenderia contra minha possível influência intelectual e moral, e, por isso, se sente mais unida. Mas não acredito que, mesmo no passado, ela se defendeu na medida e no modo dramático que ela própria supõe. E, por outro lado, será que não me defendi de sua influência e, ao mesmo 
tempo, não enriqueci e modifiquei a mim mesmo em contato com sua personalidade? (GRAMSCl, 2005b, p. 159).

Para Gramsci, a relação entre sujeitos constitui, de um lado, oportunidade para crescimento, amadurecimento individual, uma vez que a pessoa é síntese dessas relações sociais e experiências. A formação da personalidade remete à coletividade, sem dispensar o rigor e a disciplina individual. Na Carta 135, de 31 de dezembro de 1928, destinada ao irmão, Carlo, Gramsci comenta o bilhete da sobrinha, Edmea, referindo-se à ortografia:

[...] embora redija bastante bem e saiba colocar seus sentimentos em frases espontâneas e vivas, comete um número muito grande de erros de ortografia, até mesmo para um estudante que está apenas na terceira série. Deve ser um pouco cuidadosa e estar sempre apressada: suponho que, até quando fala, algumas vezes pareça um redemoinho e coma a metade das palavras, engolindo os erres com um prazer especial. Deve-se ter o cuidado de mandá-la fazer os deveres com aplicação e muita disciplina (GRAMSCl, 2005a, p. 308).

A autodisciplina constitui prérequisito relevante para os infantes e jovens em formação. Ora, segundo Gramsci, a autodisciplina é um esforço individual e também um exercício para a manutenção do vigor da vontade e organização do conhecimento. Se autodisciplina e autonomia moral constituem requisitos fundamentais à Educação, na carta 323, de 10 de agosto de 1932, Gramsci julga insuficiente uma educação cujos princípios e metodologia tenham suporte na liberdade e responsabilidade do estudante, tal como propunha a Escola Dalton existente no seu tempo, na qual os estudos ocorriam de maneira individualizada sem a obrigatoriedade de conteúdos escolares ou horários fixos de aula. Mais do que propiciar condições para o desenvolvimento da autodisciplina e da autonomia moral, desde cedo, cabe à Educação escolar o aprimoramento da capacidade da pessoa de autoanalisar concepções de mundo que formam sua personalidade. Nessa direção, o indivíduo reconhece a si mesmo como parte do processo histórico até hoje desenvolvido, pois cada um é também um bloco histórico: cada indivíduo é síntese do lugar onde nasceu geograficamente, das experiências e das relações sociais. Dessa maneira, manifesta as condições materiais e objetivas do seu tempo com os quais se relaciona.

Outro aspecto a destacar na "personalidade vigorosamente formada" se refere ao desenvolvimento de uma cultura sólida mencionada na Carta 450, escrita em dezembro de 1936:

[...] considero sempre necessário conduzir os estudantes por um caminho que permita o desenvolvimento de uma cultura sólida e realista, depurada de todo e qualquer elemento de ideologias rançosas e estúpidas, e permita a formação de uma geração que saiba construir a sua vida e a vida coletiva de modo sóbrio, com economia máxima de esforços e rendimento máximo. [...]. (GRAMSCl, 2005b, p. 412).

Dessa maneira, a infinidade de traços do processo histórico absorvidos pelo indivíduo sem análise crítica é superada pela compreensão de si mesmo como sujeito histórico-social à medida em que ocorre a "conquista progressiva da consciência da própria personalidade histórica. (GRAMSCl, 2006b, p. 79). 
Vale reiterar, a categoria "personalidade vigorosamente formada" é a base comum sobre a qual ocorre o ajuste do indivíduo e coletividade bem como o equilíbrio das capacidades do intelecto e das práticas. Nesse sentido, alguns elementos são realçados por Gramsci, tais como: o rigor, a disciplina, reconhecimento de si mesmo como parte do processo histórico e integração do pensamento, posicionamento e ação (filósofo alemão, político francês, engenheiro americano).

\section{OBSTÁCULOS PARA A “PERSONALIDADE VIGOROSAMENTE FORMADA”}

Trabalho, ciência, tecnologia, cultura e arte integram a vida humana e contribuem para o desenvolvimento integral e harmonioso das capacidades pessoais. O trabalho, a ciência, a tecnologia, no entanto, bem como a cultura e arte, assumiram outra nuance imediatamente interessada ao capital, constituindo, consequentemente, obstáculo à formação da personalidade vigorosamente coletiva.

No lugar de uma educação desinteressada (ao trabalho), ou seja, desatrelada aos interesses imediatos (relativos a trabalho), desenvolvem-se as habilidades e capacidades intelectivas e afetivas desacompanhadas de plenitude e satisfação. Por conseguinte, o principal obstáculo reside no próprio modo de vida dos trabalhadores, cujos interesses recaem, por força das relações sociais capitalista, no caráter imediato das coisas, na venda da força de trabalho como modo de sobrevivência.

Se, porém, o interesse também é uma metáfora para a conformação do trabalho ao capital, a antítese reside na educação e sociedade desinteressadas, nas quais o trabalho é verdadeiramente livre. Com efeito, não basta instituir uma educação desinteressada, uma vez que as relações sociais são interessadas. Portanto, o aprisionamento do trabalho ao capital constitui obstáculo à formação da personalidade vigorosamente formada.

Outro óbice para constituir uma "personalidade vigorosamente formada" repousa no Estado liberal - instituído e instituinte da sociedade civil. Historicamente, o Estado é caracterizado pela ineficiência e falha de administração, deixando de cumprir eficazmente suas promessas. Se o fizesse, desapareceria, diz Marx, em "O rei da Prússia e a reforma social":

[...] o estado não pode eliminar a contradição entre a função e a boa vontade da administração de um lado, e os meios e possibilidades, de outro, sem eliminar a si mesmo, uma vez que repousa sobre essa contradição. Ele repousa sobre a contradição entre a vida privada e pública, sobre a contradição entre interesses gerais e os interesses particulares. Por isso a administração deve limitar-se a uma atividade formal e negativa, uma vez que exatamente lá onde começa a vida civil e o seu trabalho cessa o seu poder. (MARX, 2010, p. 60).

É preciso ter claro o fato de que, na época de Marx, inexistiam os direitos sociais, entre eles a Educação, como os estabelecidos nos dias atuais; mas, evidentemente, o Estado não resolve os males sociais porque lhe falte capacidade técnica. A insolubilidade descansa no fato de que o Estado é expressão da sociedade civil na qual se encontram proprietários de meios de produção e não proprietários; e, consequentemente, interesses conflitantes. Por isso, aglutinam-se, no Estado, fragmentos de classes sociais distintas, cujos interesses e conflitos se transpõem para as políticas sociais, resultando em sua fragmentação e parcelarização. Em Marx, o Estado é, essencialmente, 
guardião da propriedade privada e, por isso, suas políticas postergam a solvência dos males sociais. No que concerne à educação de todas as crianças [e adolescentes, hoje], é necessário, em primeiro lugar, libertá-las da preocupação objetiva do suprimento alimentício. Com efeito,

Para educar as crianças, é preciso alimentá-las e liberá-las da necessidade de trabalhar para viver. Alimentar e educar as crianças abandonadas, isto é, alimentar e educar todo o proletariado que está crescendo, significaria eliminar o proletariado e o pauperismo (IDEM, IBIDEM).

O Estado não evoca a si a tarefa de proporcionar a todas as crianças [e jovens] o acesso a educação e alimentação, sob pena de se tornar desnecessário. Por isso, subsistem as soluções provisórias, descontínuas e destinadas à correção de procedimentos, como se fossem meras falhas administrativas. Dessa maneira, no campo educacional, as frações de classe ou grupos põem-se em disputa pelo conteúdo mínimo, aumento ou diminuição do tempo de estudo [tempo integral, meio período, carga horária de cada curso etc]; separação ou integração dos conteúdos gerais e específicos; ampliação ou redução das especializações no percurso formativo; exclusividade dos recursos públicos para instituições públicas de ensino ou permissividade do uso desses recursos pelas empresas privadas; adoção de modelos de gerenciamento extraídos das empresas privadas para as instituições públicas de ensino ou manutenção do modelo burocrático característico do controle de Estado.

Nenhuma sociedade põe para si problemas aos quais não seja capaz de resolver, já dizia Marx. Há saídas pelo portão do Estado, mas estas portas se encontram emperradas, pois o Estado não irá se destruir. Por isso, a tendência aos ajustes contínuos, econômicos e ideológicos, visando à redução de custos, à contenção de tensões sociais e ao reforçamento do individualismo. Esse processo envolve contradições e particularidades da formação econômico-social e, por isso, se constitui com suporte em alianças, continuidades e descontinuidades, concessões entre frações de classe dominante ainda que eventualmente incorpore interesses de frações da classe dominada (parafraseando Gramsci) ou dos oprimidos (categoria preferida de Paulo Freire).

Com efeito, sobrelevam-se dois obstáculos para instituir e assegurar uma formação da "personalidade vigorosamente coletiva": a conformação do trabalho ao capital e o Estado liberal.

Na seara educacional, a compreensão desses obstáculos é fundamental na elevação da consciência, evitando a adesão ao pensamento acrítico. Por isso, é relevante identificar elementos que fortalecem esses obstáculos à "personalidade vigorosamente formada" seja na sociedade civil ou no Estado.

\section{A FRAGMENTAÇÃO DO ENSINO MÉDIO BRASILEIRO CONTRAPOSTA À "PERSONALIDADE VIGOROSAMENTE FORMADA"}

No Brasil, se encontram em andamento diversas proposituras de alterações da Lei $\mathrm{n}$. 9.394/1996, envolvendo a inclusão de inúmeras disciplinas, tais como Educação no Trânsito, Ética, Cidadania, Empreendedorismo, Educação Financeira, etc. Essa afluência das disciplinas tem amparo em velhas contendas, envolvendo mais do que aspectos relacionados ao âmbito pedagógico, financeiro e da gestão. Tais proposições correspondem, decerto, às investidas liberais 
para a retomada de suas reformas educativas, a exemplo do famigerado Decreto n. 2.208/1997 e subsequentes ajustes consubstanciados nos Decretos n. 5.154/2004 e n. 8.268/2014.

Decorridos 11 anos após a revogação do Decreto n. 2.208/1997, outra propositura liberal o substitutivo do Projeto de Lei n. 6.840/2013 - vem de encontro ao sofrido Ensino Médio brasileiro. Tal Projeto de Lei tem origem no relatório apresentado à Comissão de Educação, ainda no ano de 2011. Destarte, alguns pontos foram considerados polêmicos por algumas entidades científicas e associações de profissionais ${ }^{1}$, que se contrapuseram às modificações expressas no citado projeto de lei e o subsequente substitutivo.

Essa proposta de reformulação do Ensino Médio guarda a promessa de torná-lo atraente aos jovens, uma vez que aproximadamente dois milhões de jovens de 15 a 17 anos se encontram fora da escola ao passo que sobram vagas nas instituições educacionais. Considerando essa situação, o deputado federal do Partido dos Trabalhadores de Minas Gerais, Reginaldo Lopes, propõe reforma ao Ensino Médio, cujo problema reside na persistência dos procedimentos metodológicos provenientes da escola tradicional e conservadora. Assim, o Deputado justifica a reforma, com apoio em generalizações grosseiras acerca do Ensino Médio no País, de modo que, no seu requerimento para criação de uma comissão especial para estudos, assevera o seguinte:

[...] o ensino médio ainda trata, ao mesmo tempo, de muitos temas diversos, porém, nenhum deles em profundidade, sendo que na maioria das vezes os alunos são obrigados a memorizar fórmulas, datas, princípios, que nem sempre lhes serão úteis no futuro ou contribuirão para sua formação profissional prática, tornando para muitos alunos o ensino cansativo e nem um pouco interessante. (LOPES, 2012, p. 3).

Outro aspecto a destacar revela-se na preocupação com a inexistência de parceria públicoprivado para escolas particulares ofertantes do Ensino Médio. Ora, nessa propositura, a gratuidade da Educação dentro das escolas de iniciativa privada - a serem pagas pelo Estado - permite a continuidade dos negócios em Educação e o abandono da Educação pública e gratuita.

O aspecto central dessa reforma do Ensino Médio consiste na distribuição de conteúdos em quatro direções - Biomédicas, Humanas, Ciências da Natureza e Ensino Profissional - a ser escolhida pelo estudante, conforme sua afinidade, fragmentando a cultura geral. Ora, aqui reside o principal ardil desta propositura de reforma do Ensino Médio: unidirecionamento da educação escolar dos jovens. Esse aspecto, por si, corrói as possibilidades de uma personalidade vigorosamente formada, asfixiando, no Ensino Médio, as diversas inclinações que coexistem em nós, desequilibrando o ajuste das capacidades intelectivas e práticas. Esse modelo impede, portanto, a consecução de um processo educativo capaz de reunir em um só homem o filósofo alemão, o político francês e o engenheiro americano. Dessa maneira, limita a experiência

\footnotetext{
1 Destacaram-se iniciativas tais como: a Moção 19, proveniente da organização de profissionais em torno do Movimento Nacional em Defesa do Ensino Médio, que congrega a Associação Nacional dos Profissionais em Educação (ANPED), a Associação Nacional pela Formação dos Profissionais em Educação (ANFOPE), entre outros. Para a ANFOPE, a propositura de reforma do Ensino Médio desconsidera o aspecto da formação de professores e da Lei Nacional do Piso e de Planos de Carreiras.
} 
formativa, desencoraja o pensamento autônomo e compromete a capacidade de compreensão e intervenção na realidade.

Essas características renderam ao projeto de lei supramencionado várias alterações, após a realização das diversas audiências públicas e manifestações contrárias. Com efeito, ressalto algumas preocupações acerca da Reforma do Ensino Médio, listadas na sequência:

I - Contrapõe-se à "personalidade vigorosamente formada", segmentando a cultura geral por áreas, reduzindo a capacidade de análise da realidade, comprometendo a habilidade de reconhecimento da condição de sujeito histórico da transformação social.

II - Reforça a rigidez curricular, à medida que o percurso formativo direciona o estudante a se especializar em área específica do conhecimento, ainda no Ensino Médio. $O$ estudante perde, porém, a liberdade de concorrer à vaga em curso superior em quaisquer áreas, restringindo-se à área aprofundada no Ensino Médio. Desse modo, o discurso realça aquilo que pretende esconder: rigidez pedagógica e determinismo social.

III - Enfatiza a especialização precoce, contribuindo para ampliação do estranhamento, constituindo empecilho ao reconhecimento dos fenômenos em circunstâncias socialmente postas.

Nesse sentido, a propositura de reforma do Ensino Médio brasileiro é antagônica à "personalidade vigorosamente formada", pois [a reforma] é gestada pela correlação de forças de matiz liberal, alternada com as tintas da educação para o trabalho ou pelo trabalho.

\section{CONCLUSÃO}

Para Gramsci, entre outros aspectos, é relevante o estudo de como se estruturam e se mantêm as formas de pensar que contribuem para a permanência de uma classe social dominante. Para ele, tudo o que pode influir para a opinião pública faz parte dessa estrutura, inclusive a escola. Com efeito, é relevante "dar um modelo histórico vivo de tal estrutura [pois] formaria o hábito de um cálculo mais cuidadoso e exato das forças ativas na sociedade". (2006b, p. 79).

Além do convite de Gramsci à feitura de um rigoroso estudo dessa estrutura ideológica, é preciso atentar para a organização do direcionamento da sociedade, no sentido de conferir aos seus integrantes a liberdade e igualdade transpostas ao aspecto jurídico-formal-liberal. O convite decorre de sua convicção na mudança da Educação, da escola, da imprensa, iniciando-se ainda na sociedade vigente. Afinal, para Gramsci, a Educação, a escola, a imprensa e demais instituições da sociedade civil são agentes poderosos de conservação, inclusive de transformação, e, por isso, também podem ser transformadas.

Com efeito, cabe chamar a atenção para alguns poucos corolários: 1ํ) é relevante extrair o máximo do Estado, sobretudo a Educação pública para todos, a fim de aflorar as contradições capazes de impulsionar novas conquistas sociais; 2ㅇ) é fundamental a autoanálise crítica, identificando os fragmentos das diversas concepções de mundo e reconhecendo a própria personalidade como condensação de inúmeros traços do processo histórico; 3ㅇ) é necessário comprometer-se com ideias e práticas educativas que promovam o senso de coletividade; 4ㅇ) é preciso estender a consciência da personalidade histórica às classes potencialmente aliadas por 
meio de intenso e complexo trabalho ideológico, do qual participem os professores, na condição de intelectuais orgânicos visando à remoção dos obstáculos à "personalidade vigorosamente formada"!

\section{REFERÊNCIAS BIBLIOGRÁFICAS}

1. CAPES. Banco de teses. Disponível em: <http://bancodeteses.capes.gov.br/>. Acesso em: 9 nov. 2015.

2. CONAE. Moção 19. Por uma formação humana integral - não ao retrocesso no ensino médio - contra o PL 6.840/2013. Brasília, CONAE, 2014. Disponível em: <http://conae2014.mec.gov.br/images/doc/Sistematizacao/Mocoes/19ContrariaaoPL6.pdf>. Acesso em: 17 out.2015.

3. GRAMSCl, Antonio. Cartas do Cárcere. V.1. Rio de Janeiro, Ed. Civilização Brasileira, 2005a.

4. Cartas do Cárcere. V.2. Rio de Janeiro, Ed. Civilização Brasileira, 2005b.

5. Cadernos do Cárcere. V.1. 4.ed. Rio de Janeiro, Ed. Civilização Brasileira, 2006a.

6. Cadernos do Cárcere. V.2. 4.ed. Rio de Janeiro, Ed. Civilização Brasileira, 2006b.

7. IBICT. Biblioteca digital brasileira de teses $e$ dissertações. Disponível em: <http://bdtd.ibict.br/vufind/Search/Results?join=AND\&bool0\%5B\%5D=AND\&lookfor0\%5B\% 5D=gramsci\&type0\%5B\%5D=AllFields\&page=22>. Acesso em 20 dez.2015.

8. LOPES, Reginaldo. Requerimento - requer a criação de Comissão Especial destinada a promover estudos e proposições para a reformulação do ensino médio. Brasília, Câmara dos Deputados, $2012 . \quad$ Disponível em: <http://www.camara.gov.br/proposicoesWeb/prop_mostrarintegra;jsessionid=E5228450AF D8CF25F6CA8A1425BC5468. proposicoesWeb2 ?codteor=965059\&filename $=R E Q+4337 / 2012$ >. Acesso em: 28 out. 2015.

9. MARX, Karl. Glosas críticas marginais ao artigo "O rei da Prússia e a reforma social" de um prussiano. São Paulo, Expressão popular, 2010. 